\title{
High shear dispersion of tracers in polyolefins for improving their detection
}

\author{
Valérie Massardier $^{1 *}$, Molka Louizi ${ }^{1}$, Elisabeth Maris² and Daniel Froelich² \\ ${ }^{1}$ UMR 5223 Ingénierie des Matériaux Polymères, Centre National de la Recherche Scientifique - CNRS, \\ Institut National des Sciences Appliquées de Lyon - INSA Lyon, Villeurbanne, France \\ ${ }^{2}$ Laboratoire Conception Produit Innovation, Chambéry, Arts et Métiers ParisTech, Savoie Technolac, \\ Le Bourget du Lac, France \\ *valerie.massardier@insa-lyon.fr
}

\begin{abstract}
An efficient recycling of end-of-life products is of crucial interest from an economical and ecological point of view. However, the near infrared spectroscopy often used for the optic sorting processes is limited because of the absorption of carbon black present in black plastics and as it only sorts as a function of chemical formulas. The tracing technology developed in this study is based on the dispersion of lanthanide complexes particles into polymers to give them a code that can be related to their formulation and viscosity that are important parameters for their re-processing. As the success of this technology is conditioned by achieving a fine dispersion of the tracer particles, we also focus on accomplishing a fine dispersion of tracer particles by using a high shear process. Processing under high shear rate $(\mathrm{N}=800 \mathrm{rpm}) \mathrm{has}$ proved to play a determining role in dispersing finely and homogenously tracer particles within PP matrix. Thanks to the good quality of dispersion, the detection of three tracers at a level of $0.1 \mathrm{wt} \%$ has been successfully achieved, even in black matrices for an acquisition time of $10 \mathrm{~ms}$.
\end{abstract}

Keywords: tracers, polyolefins, automated sorting, UV fluorescence, high shear extrusion, recyclability.

\section{Introduction}

The plastics success is owing to their attractive performances, inexpensive, durable materials, lightweight, recyclable, as well as adjustable properties depending on their formulation ${ }^{[1]}$. Polyolefins ${ }^{[2]}$ represent a very important family of polymers, constituting more than a third of the total plastics demand in Europe.

Recycling of post-consumer products requires their sorting that is often based on sink and float separation. This technique allows the separation of shredded plastics according to their densities ${ }^{[3]}$ but is not very efficient for separating plastics and formulations that have very close densities, such as HDPE, LDPE, PP, etc.

In addition to the existing automated sorting systems mentioned above, tracing technologies based on tracer systems can be used to refine the sorting of end-of-life products, especially those having close densities or black ones. The tracer signature is also relevant to increase the selective sorting of end-of-life products by providing a signature for polymer type and grade in complex mixtures. Tracing technologies consist in adding small amounts of tracer into plastics during the compounding process. The tracer is expected to emit a signature detectable by either magnetic or NIR detectors, UV, X-ray fluorescencespectrometry, etc. Several studies have been conducted to apply and evaluate the efficiency of tracing technologies. In the earlier 90's, $\mathrm{Ahmad}^{[4]}$ and Simmons et al. ${ }^{[5]}$ have used a tracer system to ensure a high speed positive sorting of plastic bottles. By combining three fluorescent tracers dispersed in polymers, it was possible to detect their signature by UV-spectroscopy and thus identify PEHD bottles. This technique was also successfully applied for identification of HDPE, LDPE, PP, EVA, PVC and PET polymers. In addition, the chosen tracers were compatible and chemically non-reactive with the matrices, did not affect the plastics transparency but were poorly detected in black plastics. In their study, Corbett et al. ${ }^{[6]}$ have also shown the efficiency of UV-spectroscopy to detect luminescent phosphor based molecules in white polymers for the separation of waste polymers. Other researches ${ }^{[7,8]}$ have confirmed the effectiveness of tracing technologies for enhancing the sorting of shredded wastes by simple use of flame retardants (FR) as tracers and identifying them by X-ray fluorescence spectrometry (XRF). Moreover, the near-infrared technique (NIR) can be used to detect the fluorescence of tracers based on rare earths with concentrations ranging from 0.001 to $1 \mathrm{ppm}$ in polymers. However, this method has shown its limitation to detect a signal when the matrix is black because the carbon black used as colorant significantly absorbs all of the rays in the $\mathrm{NIR}^{[9]}$.

All the above tracing techniques based on optical spectrometry have reached their limits for the tracer detection in black plastics. In fact, carbon black strongly absorbs in the ultraviolet, visible and near infrared regions and thus reduces the tracer detection. To overcome these technological limitations, Froelich et al. ${ }^{[10]}$ have proposed a comparative study on the advantages and limits of spectrometric techniques (Table 1) used for the detection of tracer systems. As a result of this study, they pointed out that the priority candidate polymers for tracing are those recognized as difficult to sort with the existing physico-chemical or optical sorting technologies. 
Table 1. A comparative study of the detection techniques used for detecting a tracer system ${ }^{[10]}$.

\begin{tabular}{|c|c|c|}
\hline Detection technique & Advantages & Limits \\
\hline \multirow{3}{*}{$\mathbf{U V}$} & High speed identification. & $\begin{array}{l}\text { Higher quantities of tracer for dark plastics } \\
\text { than for white. }\end{array}$ \\
\hline & \multirow[t]{2}{*}{ Tracer concentration: (30-100 ppm) } & Fluorescence of the polymer matrix. \\
\hline & & Clean surface detection. \\
\hline Near Infrared & High speed identification. & $\begin{array}{l}\text { Unsuitable for the identification of tracers } \\
\text { in dark plastics. }\end{array}$ \\
\hline Mid Infrared & Tracers' identification in dark plastics. & Unsuitable for high-speed identification. \\
\hline \multirow{2}{*}{$\begin{array}{l}\text { XRF } \\
\text { (X-ray fluorescence) }\end{array}$} & Tracers' identification in dark plastics. & \multirow{2}{*}{$\begin{array}{l}\text { Number of tracers limited by the Mendeleyev's } \\
\text { Periodic Table }\end{array}$} \\
\hline & High speed identification. Volume detection. & \\
\hline \multirow{2}{*}{ Magnetic detection } & \multirow{2}{*}{$\begin{array}{l}\text { Sensitivity lack with the additives contained in plastics. Proven } \\
\text { and established technology. }\end{array}$} & Only useful for binary discrimination. \\
\hline & & Requirement of high quantity of tracers. \\
\hline
\end{tabular}

They are essentially polymers that are dark-colored and have the same densities. Bezati et al. ${ }^{[11-14]}$ have shown that the $\mathrm{X}$-ray fluorescence allows the detection of few tracers, while the magnetic detection is applied for the detection of only one tracer. Furthermore, the X-ray fluorescence detection which is a volume detection, can be a reliable method for high speed identification and sorting of black plastics into different families and grades. Moreover, the tracers adapted for the XRF detection process are the elements belonging to Mendeleyev's Periodic Table (Yttrium (Y), Cerium $(\mathrm{Ce})$, etc.) and with concentration levels of about $500 \mathrm{ppm}$ or less. Nevertheless, the drawback of this study is that the choice of tracers is limited by Mendeleyev's Periodic Table elements which are neither present in polymers nor in their additives.

The choice of tracers with UV signal seems to be more opened and Lambert and Hachin ${ }^{[15,16]}$, Maris et al. ${ }^{[17]}$ have shown that tracers ( $\mathrm{T} 1$ and $\mathrm{T} 2$ ), at percentages lower than $250 \mathrm{ppm}$ were detected in white and black colored PP and ABS by UV fluorescence spectrometry as the identification technique, even after ageing standard tests.

The idea of tracing polymers for recycling seems to have potential benefits, especially to increase not only selective sorting of black colored polymers but also sorting as a function of viscosity and composition. As regards the criteria for the choice of tracers, they must be stable at processing temperatures (extrusion or injection molding conditions), non reactive, non-hazardous, non-toxic to the environment and human life, stable at climatic conditions in particular to UV radiations, non-expensive (with cost less than $0.06 € / \mathrm{kg}$ ) to facilitate their implementation in the industrial process. In addition, with regard to their detectability, tracers must have strong signal intensity, low fluorescence lifetime and well distinguished peaks to avoid overlap with other elements even in the presence of pigments and carbon black. Regarding the detection system, it must have a high detection rate per second, be able to identify rapidly tracers contained in grinded plastics (black or white) with sizes of about $20 \mathrm{~mm}$, singly or in any combination at very high speeds $(10 \mathrm{~ms})$.

The quality of detection is strongly related to the dispersion of tracers that often depends on the choices of extrusion parameters (screw profile and speed, etc). As regards the influence of twin-screw extrusion conditions, measurable extrusion characteristics were found to be of critical importance to find relationships between extrusion process, morphology development and finally polymer blends properties. In this field, different pioneering works have been carried out few years ago in twin screw extruders ${ }^{[18,19]}$. Recently, high shear processes $^{[20-23]}$ have proved to be an effective way for polymer blending. For example, high screw speed can give rise to the development of nanostructured blends with properties impossible to reach with classical processing techniques (twin-screw extruder, internal mixer, etc.). Concerning high shear extrusion, Louizi et al. ${ }^{[24,25]}$ and Bouaziz et al. ${ }^{[26]}$ have recently shown that the final morphology of polymer blends is significantly influenced by extrusion parameters such as mean residence time and screw rotation speed. Moreover, the specific mechanical energy "SME", which characterizes the extrusion process (with parameters such as torque, temperature, rotation speed, and throughput), can be correlated with the quality of the final product.

As outlined above, processing under high shear flow can provide strong shear stress on an extruded material by simple adjustment of screw rotation speeds, and thus improve the fragmentation and dispersion of tracer particles in polymer blends. Therefore, in this study, we investigate the effect of extrusion (variation of speed for a screw profile dedicated to dispersion of fillers) on the morphological development, thermal, mechanical as well as optical properties of a traced polyolefin formulation.

\section{Experimental Part}

\subsection{Materials}

The materials investigated in this study are commercial grades used in the automotive and electrical \& electronic fields: i) PP108MF97 is a white high impact polypropylene, also named (PP108 MF 97), manufactured by Sabic, made of $78 \mathrm{wt} \%$ isotactic PP and $22 \mathrm{wt} \%$ ethylene-propylene-rubber random copolymer (EPR), does not contain carbon black, its melt flow index MFI is $10 \mathrm{~g} / 10 \mathrm{~min}$ under $2.16 \mathrm{~kg}$ at $230^{\circ} \mathrm{C}$ and its specific gravity equals $0.915 \mathrm{~g} / \mathrm{cm}^{3}$; ii) BMU 133 is a black polypropylene copolymer provided by Exxon Mobil Chemicals. It contains 10\% mineral filled elastomer, shows a melt flow index MFI $=15 \mathrm{~g} / 10$ min under $2.16 \mathrm{~kg}$ at $230^{\circ} \mathrm{C}$ and a specific gravity of $0.970 \mathrm{~g} / \mathrm{cm}^{3}$. 
Three fluorescent tracers (T1, T2 and T3) were tested and belong to the inorganic family of the lanthanide complexes. T1 is an aluminium barium magnesium oxide, T2 is a doped aluminium and barium oxide, T3 is a doped vanadium trioxide. These tracers do not chemically react with the materials and were provided by the start up Tracing Technologies. They are thermally stable at high temperatures, compatible with the REACH regulations. Their essential feature is that when they are excited with a UV source between 300 and $400 \mathrm{~nm}$, they fluoresce in the visible light spectrum.

\subsection{Preparation of traced blends}

All traced blends are prepared with a co-rotating twin screw-extruder (TSE) Leistritz ZSE 18 HP. The screw profile, with a screw diameter of $18 \mathrm{~mm}$ and a L/D ratio of 60 , used for all the experiments is illustrated in Figure 1.

The originality of this extruder lies on reaching high shear rates on extruded blends by adjusting the screw rotation speed. In addition, this technique has proven to be a key to the preparation of well-dispersed silica nanofillers within polypropylene matrix. We extrapolate these results to achieve a fine dispersion of tracers within PP matrix. Indeed, a good dispersion of the tracer is required for a good detection by UV spectrometry. The chosen rotation speeds are set to 300,800 and $1200 \mathrm{rpm}$. These screw rotation speeds from 300 to 1200 rotations per minute correspond to shear rates ranging from 220 to $750 \mathrm{~s}^{-1}$ calculated thanks to Ludovic software $^{[27]}$. The extrusion temperature and the feed rate $(\mathrm{Q})$ are $200^{\circ} \mathrm{C}$ and $3 \mathrm{~kg} / \mathrm{h}$, respectively. The tracer concentration in all samples is $0.1 \%$ by weight. For each processing condition, the mean residence time is evaluated by adding one coloured pellet into the hopper. The melt temperature at the die exit is measured by introducing a thermocouple into the bulk extrudate (Table 2). These experimental parameters are determined in order to find a relationship between the extrusion process and the final properties of traced blends.

Table 2. Experimental processing parameters.

\begin{tabular}{cccc}
\hline $\begin{array}{c}\text { Screw speed } \\
(\mathbf{r p m})\end{array}$ & $\begin{array}{c}\text { Maximal } \\
\text { shear rate } \\
\left(\mathbf{s}^{-\mathbf{1}}\right)\end{array}$ & $\begin{array}{c}\text { Melt } \\
\text { temperature } \\
\left({ }^{\circ} \mathbf{C}\right)\end{array}$ & $\begin{array}{c}\text { Mean } \\
\text { residence } \\
\text { time (s) }\end{array}$ \\
\hline $\mathbf{1 0 0}$ & 140 & 210 & 85 \\
$\mathbf{8 0 0}$ & 500 & 231 & 55 \\
$\mathbf{1 2 0 0}$ & 750 & 252 & 48 \\
\hline
\end{tabular}

At the die exit of the extruder, the extrudates are pelletized and then moulded at $200^{\circ} \mathrm{C}$ through a Battenfeld 350 PLUS injection moulding machine. Standard tensile and rectangular bars are produced for mechanical tests.

\subsection{Characterization of tracers' dispersion and structure}

The structure of tracers and their dispersion in the selected polymers were investigated by Scanning Electron Microscopy (SEM) using a Hitachi S800 model at an accelerating voltage of $30 \mathrm{kV}$. Prior to observations, samples were cryo-fractured in liquid nitrogen to avoid any plastic deformation.

\subsection{Mechanical tests}

Tensile tests of the prepared blends were determined by means of an Instron machine MTS 2/M tester, at a crosshead speed of $30 \mathrm{~mm} / \mathrm{min}$ at room temperature. Impact tests were performed by means of a Zwick D7900 Type 5102-100/00 instrument in compliance with standard ISO 179 on notched specimens conditioned at $-22^{\circ} \mathrm{C}$ for $48 \mathrm{~h}$. All the reported values are averages of ten experimental results to check reproducibility.

\subsection{Thermal properties}

The thermal properties of blends before and after UV irradiation were carried out by differential scanning calorimetry using DSC Q10 of TA instruments. To perform these tests, samples were cut into pellets and placed in aluminium pans. A scan was performed from 10 to $200^{\circ} \mathrm{C}$, further maintained for $2 \mathrm{~min}$ at $200^{\circ} \mathrm{C}$ to erase the thermal history of the blends and then cooled down from $200^{\circ} \mathrm{C}$ to $10^{\circ} \mathrm{C}$. The heating and cooling rate was fixed at $10^{\circ} \mathrm{C} / \mathrm{min}$.

The degree of crystallinity, $\chi_{c}$, was calculated considering a melting enthalpy of $209 \mathrm{~J} / \mathrm{g}$ for a $100 \%$ crystalline polypropylene.

\subsection{Detection of tracer signature by UV fluorescence spectrometry}

The detection of the tracers'signal for the traced blends was performed by UV fluorescence spectrometry. The laboratory apparatus used is a UV fluorescence spectrometer Horiba Jobin Yvon type Fluomax. A $150 \mathrm{~W}$ Xenon lamp emits photons with broad energy spectrum in the range [250-900 $\mathrm{nm}$ ] (Figure 2). The photons reach the excitation monochromator which selectively transmits light

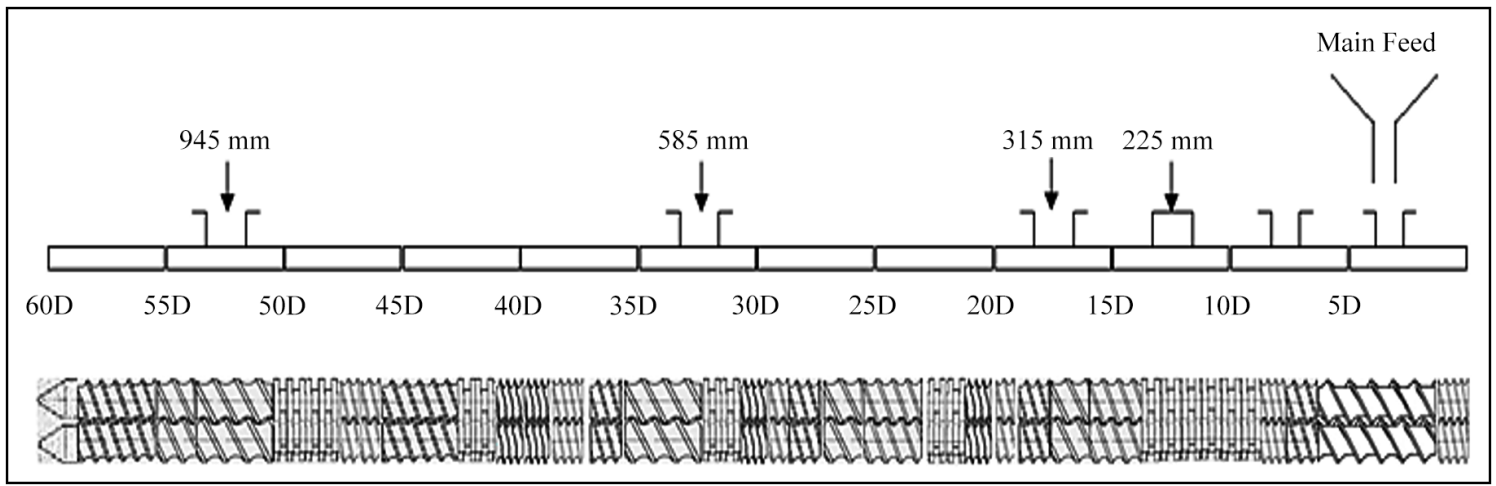

Figure 1. Screw configuration of the co-rotating high shear extruder. 
of a wavelength in a band centered on the specified excitation wavelength. The light is reflected at specific angle to the sample and then transmitted to emission monochromator. The photomultiplier signal amplifies the signal and accounts the number of photons in count per second.

Grating, sensor mirrors lenses, beam splitters have a response that depends on the wavelength and must be subtracted to the signal. The acquisition of a corrected spectrum is necessary to characterize a new component and for quantum yield measurements. The excitation spectrum is between 240 and $600 \mathrm{~nm}$ and the emission spectrum between 290 and $850 \mathrm{~nm}$.

The number of photons emitted is counted and averaged for each wavelength referring to the integration time (IT). Part of the signal is due to noise (dark count: distortion of the detector signal) and is substracted. Arbitrary unit is used for the intensity measurement.

The experimental features are excitation wavelength: $325 \mathrm{~nm}$, integration time: $0.1 \mathrm{~s}$, excitation/emission

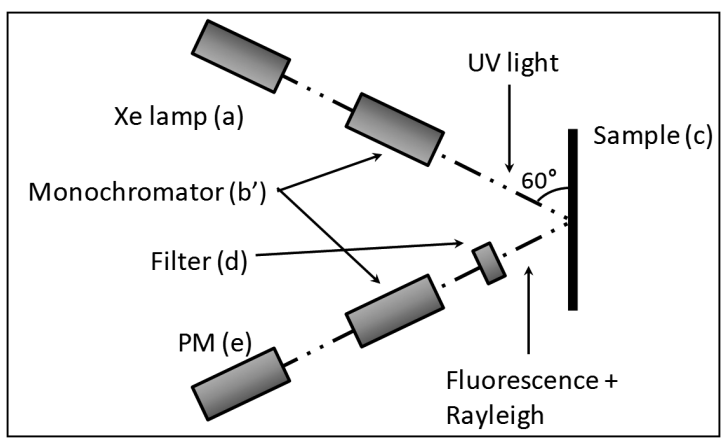

Figure 2. Scheme of the spectrometer. The source (a) is a Xe lamp of $150 \mathrm{~W}$, emitting from 240 to $850 \mathrm{~nm}$. The beam enters an excitation monochromator (b) and exits as a UV monochromatic light. The beam reaches the sample with a 60 degree incidence angle. The reflected light on the sample (c) is composed of fluorescence lines and Rayleigh scattering. Then, a high-pass filter with a $370 \mathrm{~nm}$ cut-off wavelength is added before an emission monochromator (b') and a photomultiplier (e).

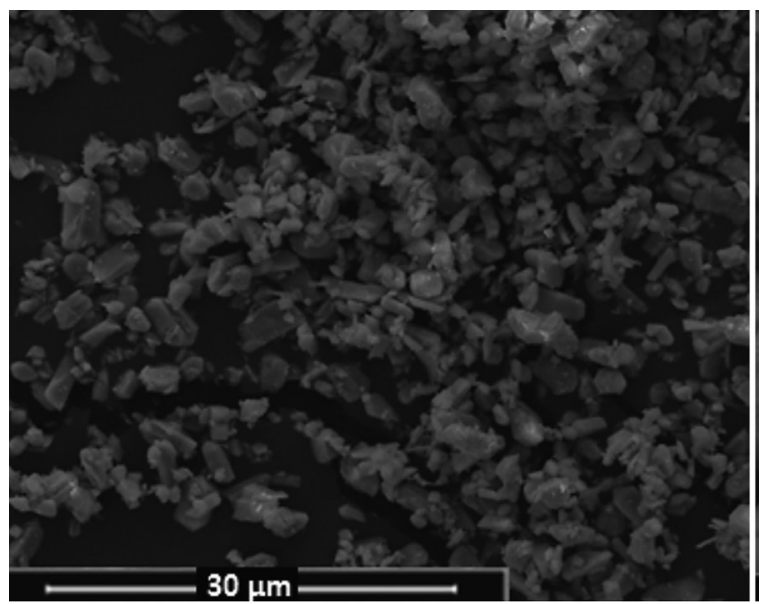

(a) monochromator slit i) for black polymer: $0.59 \mathrm{~mm} / 0.23 \mathrm{~mm}$, ii) for white polymers: $0.23 \mathrm{~mm} / 0.04 \mathrm{~mm}$.

In order to validate the UV-ray fluorescence measurements, the criteria that must be taken into account are the following: eliminate the Rayleigh scattering with a filter, search for a linearity perimeter between the intensity of the signal and concentration, validate an excitation wavelength allowing discrimination between the fluorescence of the tracers and that of the matrix. Finally, the intensity of the tracer's fluorescence signal must be greater than three times the one of the white matrix signal standard deviation in order to be validated.

Moreover, the features of the fluorescence emission are the intensity and the relative standard deviation (RSD). The intensity of tracer signal must be significantly higher than the signal of the instrument and the polymer fluorescence. The relative standard deviation (RSD) gives information about the dispersion of the tracers for the same average surface analyses.

Since the UV spectroscopy is a surface detection method, 20 measurements are carried out on the exposed surface.

\section{Results and Discussions}

\subsection{Characterization of the dispersion and structure of T3 tracer}

After validating the detection of fluorescent tracers by using UV-fluorescence spectrometry, it is another aim of this study to achieve a fine and homogenous dispersion of tracers within two PP matrices. Indeed, an efficient dispersion of tracer particles is of great importance since it may not only improve their detection but also lead to enhanced mechanical properties of traced blends ${ }^{[14,28]}$.

Before proceeding to the characterization of tracer's dispersion, in the first instance, it was appropriate to examine the structure of $\mathrm{T} 3$ tracer which was delivered in micrometer powder. A concise analysis was carried out by Scanning Electron Microscopy (SEM) to evaluate its structure.

As clearly seen from SEM micrographs taken at different magnifications (Figure 3), the T3 powder is organized

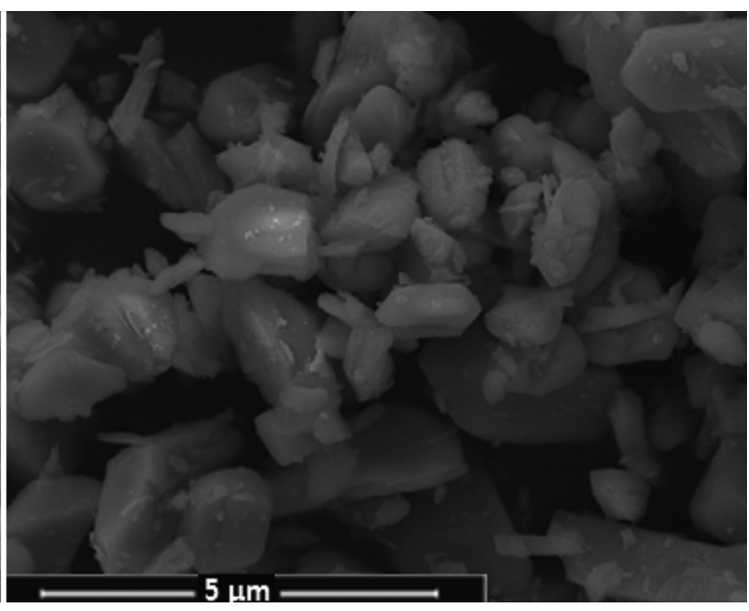

(b)

Figure 3. SEM image of the micrometric $\mathrm{T} 3$ tracer as received. 
in form of sticks which aggregate together to form large agglomerates. In order to separate these agglomerates into finer particles, it is necessary to apply strong forces. That is why a high-shear extruder is used for preparing traced blends. This recent generation of extruder is of scientific importance and possesses a profound prospect in industrial applications: it facilitates the dispersion of fillers in matrices thanks to strong shear forces by simply adjusting the screw rotation speed without any additive $\mathrm{e}^{[2,30]}$.

To highlight the high shear effect, the micrographs displayed in Figure $4 \mathrm{a}$ and $\mathrm{b}$ depict the morphologies of traced blends ((PP108 MF 97-T3-0.1) and (BMU133-T3-0.1)) as a function of the screw speed, respectively $100 \mathrm{rpm}$ (a) and $800 \mathrm{rpm}(\mathrm{b})$.

For the traced blends (PP108 MF97-T3-0.1) processed under low shear rate (100 rpm), numerous agglomerates of $\mathrm{T} 3$ tracer are seen on SEM micrographs (Figure 4a) with sizes ranging from 2 to $5 \mu \mathrm{m}$ inducing agglomeration problems as well as heterogeneous distribution. This can be ascribed to the inadequacy of the applied shear rate (i.e. $220 \mathrm{~s}^{-1}$ ) during compounding to break agglomerates into finer ones. Interestingly, by increasing the screw rotation speed up to $800 \mathrm{rpm}$, the size of tracer agglomerates is reduced to less than $80 \mathrm{~nm}$ and a homogeneous dispersion of these particles is achieved, leading to decreased distances between particles. (Figure 4b). This finer dispersion is due to the high shear stresses (from 220 to $550 \mathrm{~s}^{-1}$ ) applied on the tracer agglomerates and resulting in their division into finer ones within PP matrices. Such an effect was recently observed by other authors ${ }^{[31,32]}$. They showed that the rotation speed increase, which mainly controls the shear conditions during extrusion, has a high influence on the dispersion of fillers.

As regards the black colored traced polymer (BMU133-T3-0.1), it is not easy to distinguish tracers in form of particles or agglomerates. Apparently, the presence of other additives such as mineral fillers and carbon black contained in BMU 133 polymer can mask the T3 tracer.

\subsection{Mechanical properties}

By means of SEM observations, it is shown that the increase of screw speed greatly impacts the dispersion of tracer particles within the polyolefin matrices; consequently, the mechanical properties should also be influenced. Indeed, a homogenous and fine dispersion of fillers induces an improvement of the mechanical properties of materials, such as poor dispersion as well as presence of agglomerates that lead to structural defects. To evaluate the effect of adding tracers on the mechanical properties of traced polymers as a

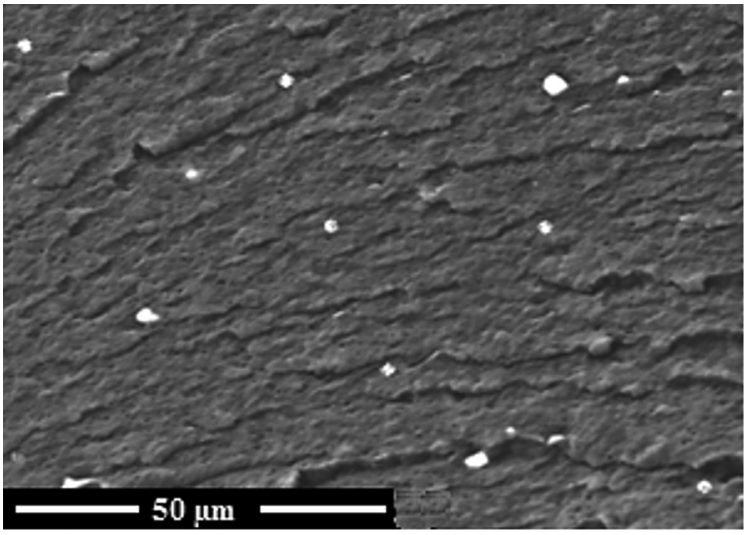

(a)

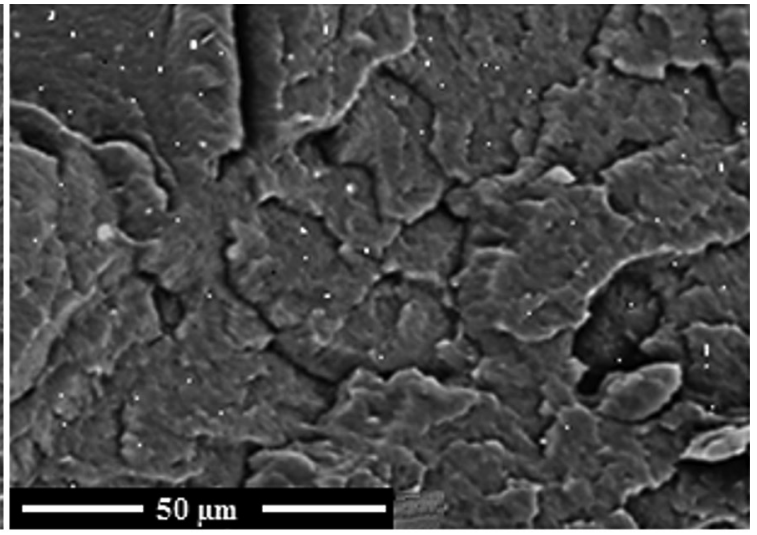

(b)

Figure 4. Morphologies of PP108 MF 97-T3- 0.1 traced blends extruded at (a) $100 \mathrm{rpm}$ and (b) $800 \mathrm{rpm}$.

Table 3. Mechanical properties of PP108 MF 97 and BMU 133 polymers as received and their traced blends processed at various screw speeds.

\begin{tabular}{|c|c|c|c|c|}
\hline Samples & $\begin{array}{c}\mathbf{E} \\
(\mathrm{MPa}) \\
\end{array}$ & $\begin{array}{c}\sigma \mathrm{m} \\
(\mathrm{MPa})\end{array}$ & $\begin{array}{c}\mathrm{cb} \\
(\%) \\
\end{array}$ & $\begin{array}{c}\text { Impact Strength } \\
\left(\mathrm{kJ} / \mathrm{m}^{2}\right)\end{array}$ \\
\hline PP108 MF 97-reference (W) & $450 \pm 10$ & $20 \pm 10$ & $530 \pm 04$ & $8 \pm 01$ \\
\hline PP108 MF 97-T3- 0.1 (100 rpm) & $470 \pm 10$ & $19 \pm 05$ & $480 \pm 10$ & $6 \pm 02$ \\
\hline PP108 MF 97-T3- 0.1 (800 rpm) & $440 \pm 08$ & $20 \pm 06$ & $570 \pm 05$ & $14 \pm 01$ \\
\hline PP108 MF 97-T3- 0.1 (1200 rpm) & $280 \pm 04$ & $19 \pm 04$ & $410 \pm 10$ & $9 \pm 01$ \\
\hline BMU133-reference (B) & $420 \pm 10$ & $13 \pm 03$ & $187 \pm 10$ & $7 \pm 01$ \\
\hline BMU133-T3- 0.1 (100 rpm) & $453 \pm 05$ & $12 \pm 05$ & $106 \pm 20$ & $6 \pm 01$ \\
\hline BMU133-T3- 0.1 (800 rpm) & $410 \pm 08$ & $13 \pm 06$ & $251 \pm 10$ & $12 \pm 01$ \\
\hline BMU133-T3- 0.1 (1200 rpm) & $283 \pm 07$ & $12 \pm 02$ & $145 \pm 10$ & $8 \pm 01$ \\
\hline BMU133-T2- 0.1 (100 rpm) & $461 \pm 04$ & $12 \pm 01$ & $136 \pm 03$ & $7 \pm 02$ \\
\hline BMU133-T2- 0.1 (800 rpm) & $430 \pm 08$ & $13 \pm 08$ & $224 \pm 02$ & $11 \pm 02$ \\
\hline BMU133-T2- 0.1 (1200 rpm) & $245 \pm 02$ & $11 \pm 05$ & $132 \pm 08$ & $6 \pm 01$ \\
\hline
\end{tabular}

W: white polymer; B: black polymer. 
function of screw rotation speeds (100, 800 and $1200 \mathrm{rpm})$, tensile stress $\left(\sigma_{\mathrm{m}}\right)$, tensile modulus $(\mathrm{E})$, elongation at break $\left(\varepsilon_{\mathrm{b}}\right)$ and impact strength are investigated and summarized in Table 3.

As reported in Table 3, on one hand, the addition of tracer particles to the selected polymers induces a slight increase of Young's modulus from 20 to $40 \mathrm{MPa}$, compared to PP matrix. This increase is not significantly important and can be induced by the reinforcing effect of tracer particles. Furthermore, the elongation at break decreases for all traced polymers processed at $100 \mathrm{rpm}$. This decrease must be related to the extended agglomeration of tracer particles as observed earlier in Figure 4. These tracer agglomerates can act as stress concentrators, initiate the specimen fracture and cause mechanical failure points. On the other hand, it can be observed that by increasing the screw speed up to $800 \mathrm{rpm}$, the elongation at break and impact strength values of traced formulations are close to the ones of the polymers as received, as extrusion at screw speed of $800 \mathrm{rpm}$ significantly increases the mechanical properties of neat $\mathrm{PP} / \mathrm{EPR}^{[23]}$. Similarly, Louizi et al. ${ }^{[25]}$ have shown that the increase of screw speed leads to higher mechanical energy (SME), which quantifies the level of energy transferred to the blends by mechanical input during extrusion ${ }^{[24,33]}$. They have shown that the breakup of agglomerates (such as silica ones) in a PP matrix is favoured by high shear rates and results in a greater dispersion of the fillers.

For polymer blends, Teyssandier et al. ${ }^{[23]}$ have observed improved elongation at break and impact strength values for polyamide 12 (PA12)/plasticized starch blends processed at high-shear rates. This improvement is attributed to very fine dispersion of starch particles in the PA12 matrix.

Nonetheless, all the traced blends processed at $1200 \mathrm{rpm}$ reveal a noticeable reduction in mechanical properties owing to the degradation of the PP polymer chains resulting from all the thermal and mechanical history experienced by the polymer blends during the process ${ }^{[34,35]}$.

Obviously, by examining the experimental processing parameters reported in Table 2, it can be noted that the increase of the screw speed from 800 to $1200 \mathrm{rpm}$ induces self heating leading to a sharp increase of the extruder exit temperature from 232 to $252^{\circ} \mathrm{C}$ as well as a slight decrease in mixing time from 55 to $48 \mathrm{~s}$. Thus, processing under high shear rate $(800 \mathrm{rpm})$ plays a determining role in dispersing finely and homogenously the tracer particles within PP matrix; this is fundamental for the conservation or even enhancement of the mechanical properties of the traced blends.

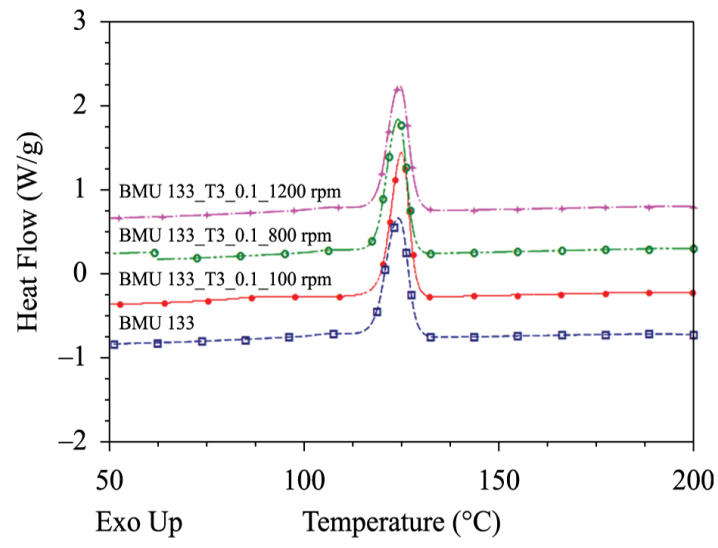

(a)

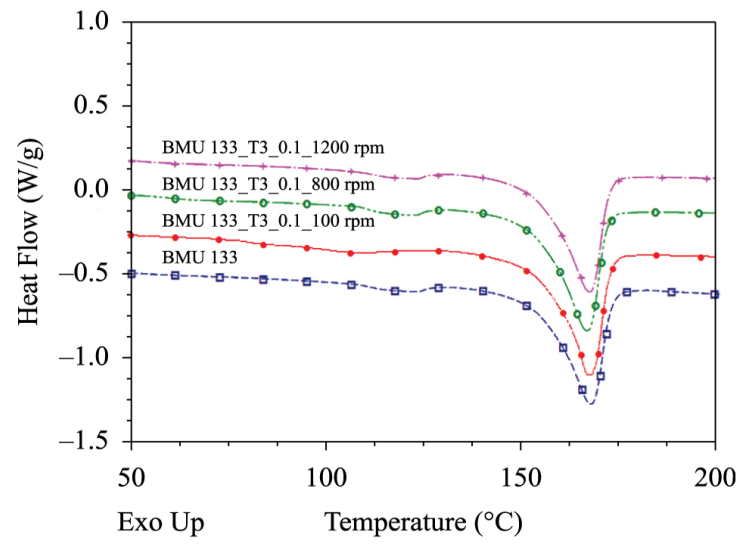

(b)

Figure 5. Crystallization (a) and melting (b) peaks of BMU 133 with T3 tracer.

Table 4. Thermal properties and crystallinity degrees (obtained by DSC and TGA) of PP108 MF 97 and BMU 133 polymers as received and their traced blends processed at various screw speeds.

\begin{tabular}{lccccc}
\hline \multicolumn{1}{c}{ Samples } & $\begin{array}{c}\mathbf{T}_{\mathrm{m}} \\
\left({ }^{\circ} \mathbf{C}\right)\end{array}$ & $\begin{array}{c}\Delta \mathbf{H}_{\mathrm{f}} \\
\left(\mathbf{J} / \mathbf{g}_{\mathrm{PP}}\right)\end{array}$ & $\begin{array}{c}\mathbf{T}_{\mathbf{c}} \\
\left({ }^{\circ} \mathbf{C}\right)\end{array}$ & $\begin{array}{c}\Delta \mathbf{H}_{\mathbf{c}} \\
\left(\mathbf{J} / \mathbf{g}_{\mathrm{PP}}\right)\end{array}$ & $\begin{array}{c}\mathbf{X}_{\mathrm{c}} \\
(\mathbf{\%})\end{array}$ \\
\hline PP108 MF 97-reference (W) & $\mathbf{1 6 7 . 5}$ & $\mathbf{5 3 . 3}$ & $\mathbf{1 3 2 . 3}$ & $\mathbf{5 8 . 8}$ & $\mathbf{2 5 . 5}$ \\
PP108 MF 97-T3-0.1-100 rpm & 168.1 & 55.2 & 131.7 & 60.7 & 26.4 \\
PP108 MF 97-T3-0.1-800 rpm & $\mathbf{1 6 7 . 8}$ & $\mathbf{5 8 . 3}$ & $\mathbf{1 3 2 . 3}$ & $\mathbf{6 3 . 4}$ & $\mathbf{2 7 . 8}$ \\
PP108 MF 97-T3- 0.1-1200 rpm & 166.7 & 55.8 & 132.5 & 62.2 & 26.7 \\
BMU133-reference (B) & $\mathbf{1 6 8 . 2}$ & $\mathbf{5 1 . 2}$ & $\mathbf{1 2 4}$ & $\mathbf{5 7 . 1}$ & $\mathbf{2 4 . 5}$ \\
BMU133-T3- 0.1-100 rpm & 167.5 & 53.7 & 125 & 59.3 & 25.7 \\
BMU133-T3-0.1-800 rpm & $\mathbf{1 6 7 . 1}$ & $\mathbf{5 5 . 2}$ & $\mathbf{1 2 4}$ & $\mathbf{6 2 . 4}$ & $\mathbf{2 6 . 5}$ \\
BMU133-T3-0.1-1200 rpm & 167.4 & 54.4 & 124 & 59.1 & 26.0 \\
BMU133-reference (B) & $\mathbf{1 6 8 . 2}$ & $\mathbf{5 1 . 2}$ & $\mathbf{1 2 4}$ & $\mathbf{5 7 . 1}$ & $\mathbf{2 4 . 5}$ \\
BMU133-T2- 0.1-100 rpm & 168.4 & 55.8 & 124 & 60.3 & 26.6 \\
BMU133-T2- 0.1-800 rpm & $\mathbf{1 6 7 . 2}$ & $\mathbf{5 7 . 1}$ & $\mathbf{1 2 4}$ & $\mathbf{6 3 . 2}$ & $\mathbf{2 7 . 3}$ \\
BMU133-T2-0.1-1200 rpm & 168.5 & 54.8 & 123 & 58.3 & 26.2 \\
\hline
\end{tabular}




\subsection{Thermal properties}

The effect of adding $\mathrm{T} 3$ and $\mathrm{T} 2$ tracers on the thermal properties of traced blends processed at various screw speeds were analyzed by differential scanning calorimetry (DSC) and thermogravimetric analyses under nitrogen (Figure 5 and 6). Table 4 summarizes the results, listing the melting/crystallization temperatures as well as crystallization/ melting enthalpies of traced blends. In addition, the temperature at maximum weight loss $\left(\mathrm{T}_{\max }\right)$ which is defined at the peak of the derivative of the TGA curves has been measured (Table 4). Whatever the screw rotation, the addition of tracer particles at a concentration of $0.1 \%$ to the black or white PP matrix does neither affect their melting nor their crystallization temperatures.

Nevertheless, at $\mathrm{N}=800 \mathrm{rpm}$, the tracer particles seem to increase slightly the crystallinity degree of $\mathrm{PP}$, which suggests that added particles may behave like centers of germination and nucleation. Such a behavior was already observed by Liu et al. ${ }^{[36]}$ who found that fine powders of rare earth oxides may act as nucleators and influence the growth rate of polypropylene spherulites. The study of Xiaomin et al. ${ }^{[37]}$ shows that the addition of $1 \mathrm{wt} \%$ of yttrium oxide $\left(\mathrm{Y}_{2} \mathrm{O}_{3}\right)$ as a tracer acts as a nucleating agent and increases the crystallinity degree of the investigated polymer. However, recently, Bezati et al. ${ }^{[11,14]}$ have shown that the dispersion of $0.1 \%$ cerium oxide to a PP matrix, under classical extrusion conditions, does not influence the thermal properties.

Thus, extrusion at a high screw speed of $800 \mathrm{rpm}$ (Table 4) seems to improve the dispersion of our fillers that can act as nucleating agents able to increase the cristallinity degree.

However, TGA reveals that the variation of screw rotation does not affect the thermal stability of the traced blends (Figure 6).

\subsection{Detection of tracers using UV-fluorescence spectrometry}

The first objective is to show the three fluorescent tracers are detected in both white and black polyolefin matrices. The excitation wavelength is the same for each tracer. The three fluorescence emission wavelengthes correspond to green, blue and red colours (Figure 7). Fluorescence emission spectrum of T3 displays several peaks characteristic of rare earth complexes with peak width of about $5 \mathrm{~nm}$ at its base. $\mathrm{T} 1$ and $\mathrm{T} 3$ tracers both display one peak with peak width of about respectively 50 and $100 \mathrm{~nm}$ at their base. The fluorescence lifetime is of about $10^{-3} \mathrm{~s}$ for lanthanide complexes and of about only $10^{-9} \mathrm{~s}$ for organic tracers. The commercial tracers (T1, T2 and T3) were primarily selected on the basis of their good excitation wavelength in the [310-370 nm] spectral band range as well as of their fluorescence emission band signatures in the visible band range of the spectrum. As shown in the spectra, the signature of each tracer, at concentration rates of $0.1 \mathrm{wt} \%$, is clearly visible and distinguishable from the "background" sample. It seems that the signal of the T3 tracer is more intense than those of $\mathrm{T} 1$ and $\mathrm{T} 2$ tracers. The $\mathrm{T} 3$ tracer is very interesting for the rest of the study because, as its signal intensity is the most important, it can be added to the polymer matrix in less than $1000 \mathrm{ppm}$, down to $30 \mathrm{ppm}$ as was already verified by laboratory equipments. In what follows, we have focused the experiments on blends with $\mathrm{T} 3$ and $\mathrm{T} 2$ tracers at $1000 \mathrm{ppm}$ concentration to analyze their influence on the final properties of traced blends. As T3 does, tracers can display several peaks, which can facilitate their detection. Inorganic tracers often present finer peaks than inorganic ones, which are more easily distinguishable from the polymer fluorescence peaks.

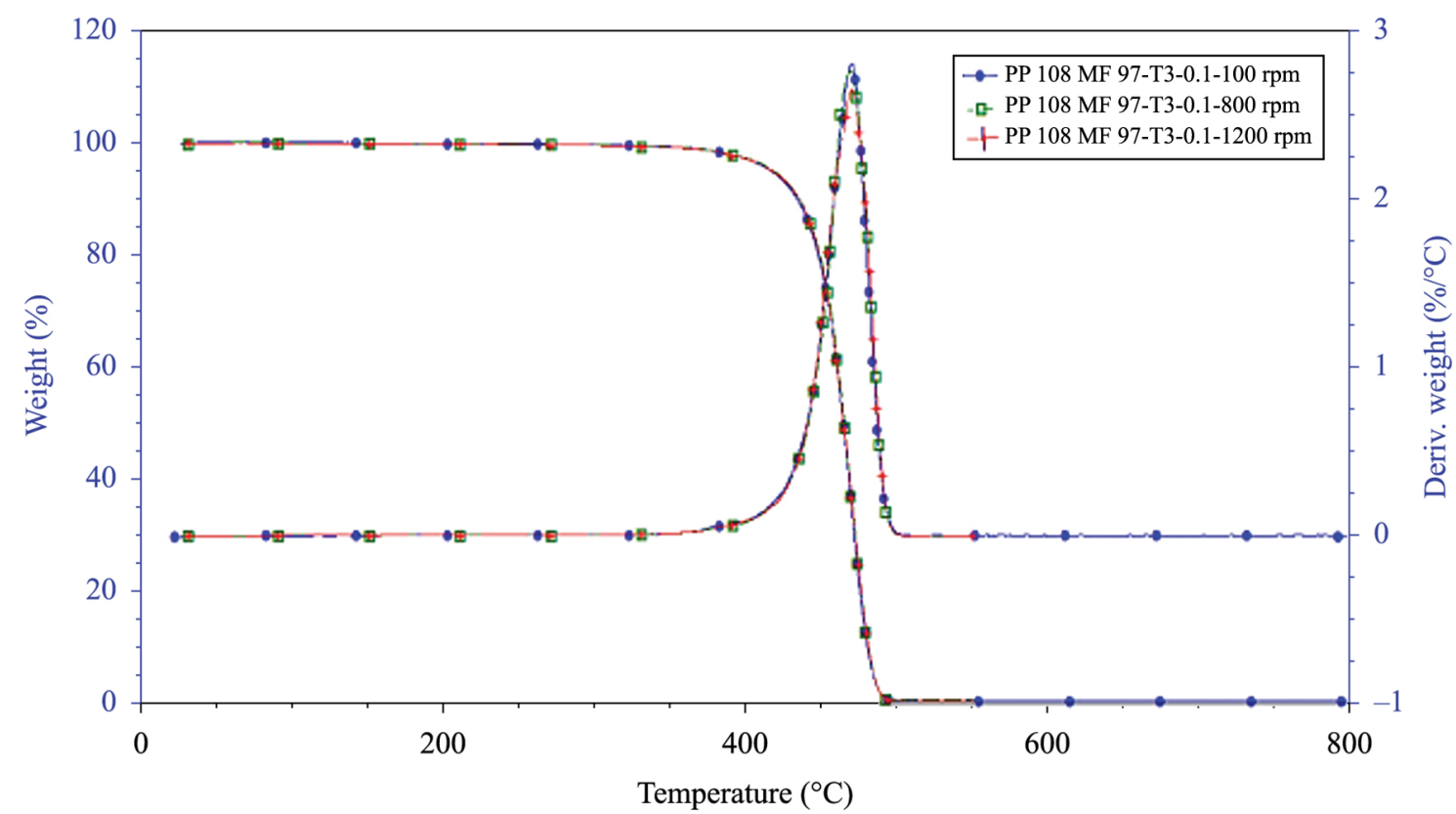

Figure 6. TGA curves of PP108 MF 97-T3-0.1 traced blends processed at different screw speeds (100, 800 and $1200 \mathrm{rpm})$. 


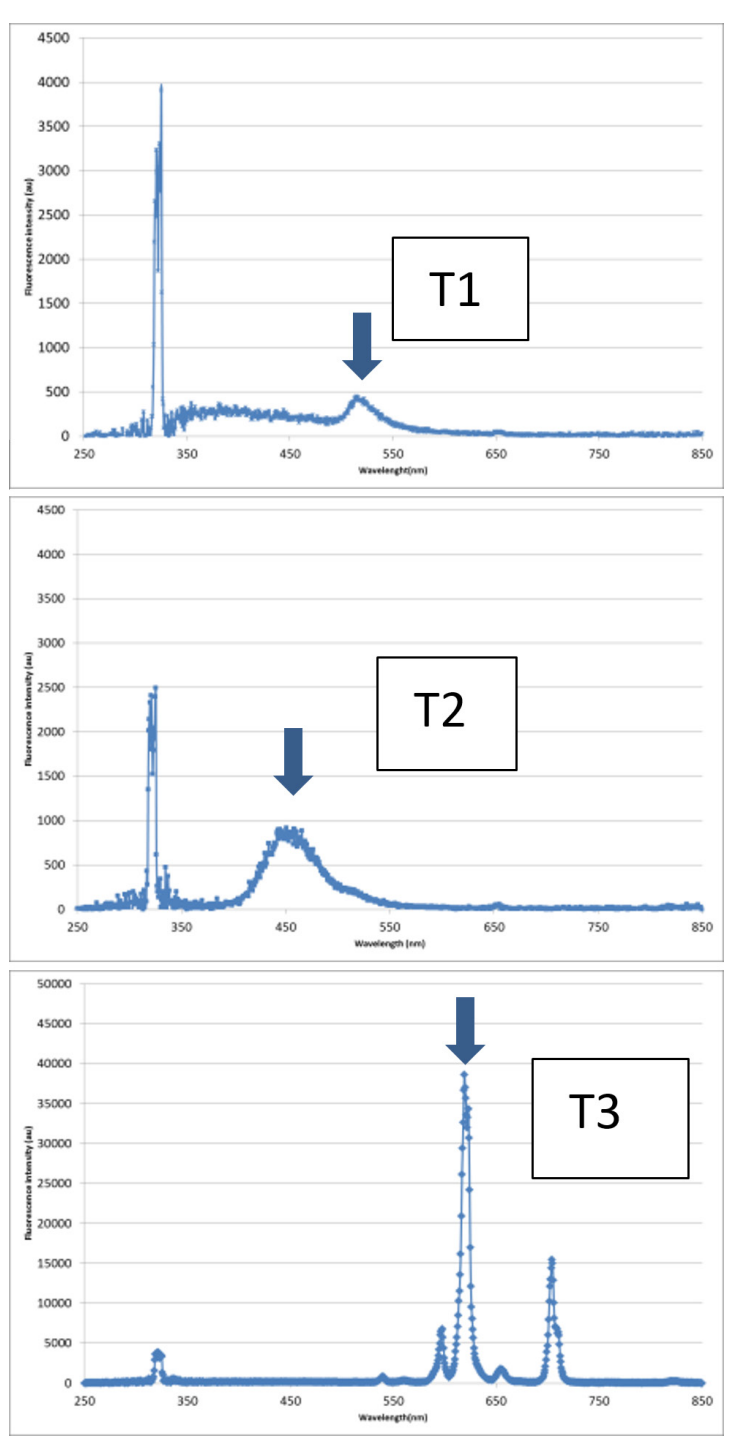

Figure 7. Spectra of virgin black BMU 133 with T1, T2, T3 tracers at concentrations of $1000 \mathrm{ppm}$.

Table 5a. Measured values of UV-detection of traced white blends (PP108 MF 97-T3) processed at various screw speeds.

\begin{tabular}{lccc}
\multicolumn{1}{c}{ Traced blends } & AFI $^{1}$ & SD $^{\mathbf{2}}$ & RSD $^{\mathbf{3}}$ \\
\hline PP108 & $4.8 \mathrm{E}+07$ & $9.3 \mathrm{E}+06$ & $\mathbf{1 9 \%}$ \\
MF 97-T3-0.1-100 rpm & & & \\
PP108 & $5.8 \mathrm{E}+07$ & $8.1 \mathrm{E}+06$ & $\mathbf{1 4 \%}$ \\
$\begin{array}{l}\text { MF 97 -T3-0.1-800 rpm } \\
\text { PP108 }\end{array}$ & $6.1 \mathrm{E}+07$ & $8.5 \mathrm{E}+06$ & $\mathbf{1 4 \%}$ \\
MF 97-T3-0.1-1200 rpm & & & \\
\hline
\end{tabular}

1: Average Fluorescence Intensity. 2: Standard Deviation. 3: Relative Standard Deviation.

\subsection{Study of the relation between dispersion and detection of tracers}

Since the shear rate exerted during melt mixing has shown a significant influence on the dispersion as well as on the distribution of tracer particles, the average fluorescence intensity should also be enhanced. From Table 5a, it can be observed that the processing of traced blends at
Table 5b. Measured values of UV-detection of traced black blends containing T3 or T2 tracers (BMU 133-T2-0.1 and BMU 133-T3$0.1)$ processed at $800 \mathrm{rpm}$.

\begin{tabular}{lcc}
\hline \multicolumn{1}{c}{ Traced blends } & BMU133-T2-0.1 & BMU133-T3-0.1 \\
\hline $\begin{array}{l}\text { (800 rpm) } \\
\text { Average Fluorescence } \\
\text { intensity (AFI) }\end{array}$ & $1.9 \mathrm{E}+06$ & $1.1 \mathrm{E}+06$ \\
$\begin{array}{l}\text { Standard deviation } \\
\text { (SD) }\end{array}$ & $4.1 \mathrm{E}+05$ & $2.6 \mathrm{E}+05$ \\
$\begin{array}{l}\text { Relative standard } \\
\text { deviation (RSD) }\end{array}$ & $\mathbf{2 1 \%}$ & $\mathbf{2 2 \%}$ \\
\hline
\end{tabular}

$\mathrm{N}=800$ and $1200 \mathrm{rpm}$ displays lower relative standard deviation for the measurements of fluorescence intensity compared to the traced blends processed at $100 \mathrm{rpm}$. This is ascribed to the fine dispersion of tracer particles within the PP matrix obtained when processing at high shear rates. As the conservation of mechanical properties and good detection of tracers are two necessary conditions for the success of the tracing technology, in what follows, the UV-detection is achieved only for samples processed at $800 \mathrm{rpm}$. In fact, the processed samples at $1200 \mathrm{rpm}$ show failures in mechanical properties (Table 3).

As $800 \mathrm{rpm}$ is a good compromise for both detection and maintenance of mechanical properties, the BMU 133 based black formulation has been processed at this rate and the detection of both $\mathrm{T} 2$ and $\mathrm{T} 3$ is good.

As clearly shown in Table $5 b$, the average fluorescence signal of black traced blends is less intense than for white ones. The signal is attenuated by the presence of carbon black, but the signal/noise ratio is sufficiently high for the detection to be positive. It is worth noting that the dispersion of $0.1 \mathrm{wt} \%$ of T2 or T3 tracer in the PP copolymer containing $1 \mathrm{wt} \%$ of carbon black is more difficult to accomplish compared to the white PP because of lower fluidity of the black colored formulation. When processing at $800 \mathrm{rpm}$, the relative standard deviation of fluorescence intensity of BMU 133-T2-0.1 and BMU133-T2-0.1 is higher (respectively around $21 \%$ and 24\%) compared to the white PP108MF97-T3-0.1 (14\%).

\section{Conclusion}

Based on this research, high shear process (800 rpm) has proved to play a determining role in dispersing finely and homogenously tracer particles within PP matrix. Such an effect is fundamental for the conservation of mechanical properties of traced blends and for enhancing the detection of tracers. Interestingly, it appears that the concept of tracing polymers could be a key for the high speed identification and automated on-line sorting of black plastics into different families and grades. The detection of three tracers (T1, T2 and T3) at a level of $0.1 \mathrm{wt} \%$ in black matrices was successfully achieved through the use of UV-ray fluorescence spectrometry. In conclusion, this research contributes to the improvement of the recyclability of white and black-coloured polymers and can be applied also for polymers having similar densities. Furthermore, it can be used as a guideline for tracing polymers to increase the rate of automatic sorting. 


\section{Acknowledgements}

The authors would like to thank the National Research Agency (ANR) for its contribution to the funding of this work and for providing industrial orientations and scientific supervision to the research. Authors also wish to acknowledge P. Alcouffe and the "Centre de Microstructures et d'analyses, plateforme Lyon 1" of the University Lyon 1 for his assistance in the SEM characterization and valuable discussions.

\section{References}

1. Aouachria, K., Quintard, G., Massardier-Nageotte, V., \& Belhaneche-Bensemra, N. (2014). The effect of di-(-2-ethyl hexyl) phthalate (dehp) as plasticizer on the thermal and mechanical properties of pvc/pmma blends. Polímeros. Ciência e Tecnologia, 24(4), 428-433. http://dx.doi.org/10.1590/01041428.1588 .

2. Plastics Europe. (2013). Plastics - the facts 2013. An analysis of European latest plastics production, demand and waste data. Belgium: Plastics Europe. Retrieved in 12 November 2014, from http://www.plasticseurope.org/documents/ document/20131014095824-final_plastics_the_facts_2013 published_october2013.pdf

3. Altland, B. L., Cox, D., Enick, R. M., \& Beckman, E. J. (1995). Optimization of the high-pressure, near-critical liquid-based microsortation of recyclable post-consumer plastics. Resources, Conservation and Recycling, 15(3-4), 203-217. http://dx.doi. org/10.1016/0921-3449(95)00031-3.

4. Ahmad, S. R. (2004). Anew technology for automatic identification and sorting of plastics for recycling. Environmental Technolology, 25(10), 1143-1149. Retrieved in 12 November 2014, from http:// www.tandfonline.com/doi/abs/10.1080/09593332508618380

5. Simmons, B. A., Overton, B. W., Viriot, M., Ahmad, S. R., Squires, D. K., \& Lambert, C. (1998). Fluorescent tracers enable automatic identification and sorting of waste plastics. British Plastics and Rubber, 8, 4-12.

6. Corbett, E. C., Frey, J. G., Grose, R. I., Hendra, P. J., \& Taylorbrown, T. (1994). An investigation into the applicability of luminescent tagging to polymer recovery. Plastics Rubber and Composites Processing and Applications, 21(1), 5-11. Retrieved in 12 November 2014, from http://eprints.soton. ac.uk/id/eprint/15926

7. Maris, E., Froelich, D., Lambert, C., \& Hachin, J-M. (2015). FR Patent No 3010789 (A3). Paris: TRACING TECHNOLOGIES Société à responsabilité limitée. Retrieved in 12 November 2014, from http://worldwide.espacenet.com/publicationDetails/ biblio? $\mathrm{DB}=$ worldwide.espacenet.com $\& \mathrm{II}=0 \& \mathrm{ND}=3 \&$ adjace $\mathrm{nt}=$ true $\&$ locale $=$ en $E P \& F T=$ D\&date $=20150320 \& C C=F R \&$ $\mathrm{NR}=3010789 \mathrm{~A} 3 \& \overline{\mathrm{K}} \mathrm{C}=\mathrm{A} 3$

8. American Plastics Council (2003). An industry full of potential: ten facts to know about plastics from consumer electronics. Virginia: APC. Retrieved in 12 November 2014, from http:// plastics.americanchemistry.com/An-Industry-Full-of-PotentialConsumer-Electronics

9. Eisenreich, N., Kull, H., \& Thinnes, E. (1992). Rapid identification of plastics with fast near-infrared spectroscopy. In Proceedings of the 23rd International Annual Conference of ICT: waste management of energetic materials and polymers ( $\mathrm{pp}$. S.59.1-59.12). Karlsruhe: Fraunhofer-Institut für Chemische Technologie.

10. Froelich, D., Maris, E., Haoues, N., Chemineau, L., Renard, H., Abraham, F., \& Lassartesses, R. (2007). State of the art of plastic sorting and recycling: feedback to vehicle design. Minerals Engineering, 20(9), 902-912. http://dx.doi.org/10.1016/j. mineng.2007.04.020.

11. Bezati, F., Froelich, D., Massardier, V., \& Maris, E. (2010). Addition of tracers into the polypropylene in view of automatic sorting of plastic wastes using X-ray fluorescence spectrometry. Waste Management (New York, N.Y.), 30(4), 591-596. http:// dx.doi.org/10.1016/j.wasman.2009.11.011. PMid:20018501.

12. Bezati, F., Massardier, V., Froelich, D., Maris, E., \& Balcaen, J. (2010). Elaboration and characterization of traced polypropylene with rare earth oxides for automatic identification and sorting of end-of-life plastics. Waste and Biomass Valorization, 1(3), 357-365. http://dx.doi.org/10.1007/s12649-010-9028-4.

13. Bezati, F., Froelich, D., Massardier, V., \& Maris, E. (2011). Addition of X-ray fluorescent tracers into polymers, new technology for automatic sorting of plastics: proposal for selecting some relevant tracers. Resources, Conservation and Recycling, 55(12), 1214-1221. http://dx.doi.org/10.1016/j. resconrec.2011.05.014.

14. Bezati, F., Massardier, V., Balcaen, J., \& Froelich, D. (2011). A study on the dispersion, preparation, characterization and photo-degradation of polypropylene traced with rare earth oxides. Polymer Degradation \& Stability, 96(1), 51-59. http:// dx.doi.org/10.1016/j.polymdegradstab.2010.11.008.

15. Lambert, C., Hachin, J. M. (2010). FR Patent No WO2010012892A2. Paris: TRACING TECHNOLOGIES Société à responsabilité limitée. Retrieved in 12 November 2014, from http:// worldwide.espacenet.com/searchResults?ST=singleline\&1 ocale $=$ en_EP\&submitted $=$ true $\& D B=$ worldwide. espacenet. com\&query $=$ WO2010012892

16. Lambert, C., \& Hachin, J. M. (2010). US Patent No 2010089804 A1. Paris: TRACING TECHNOLOGIES Société à responsabilité limitée. Retrieved in 12 November 2014, from http://worldwide. espacenet.com/publicationDetails/biblio?DB=worldwide. espacenet.com $\& I I=4 \& N D=3 \&$ adjacent $=$ true $\&$ locale $=$ en_EP $\& \mathrm{FT}=\mathrm{D} \&$ date $=20100415 \& \mathrm{CC}=\mathrm{US} \& \mathrm{NR}=2010089804 \mathrm{~A} 1 \& \mathrm{~K}$ $\mathrm{C}=\mathrm{A} 1$

17. Maris, E., Aoussat, A., Naffrechoux, E., \& Froelich, D. (2012). Polymer tracer detection systems with UV fluorescence spectrometry to improve product recyclability. Minerals Engineering, 29, 77-88. http://dx.doi.org/10.1016/j.mineng.2011.09.016.

18. Lim, S., \& White, J. L. (1994). Influence of a compatibilizing agent on the phase morphology of a polyethylene-polyamide 6 blend in a modular intermeshing co-rotating twin screw extruder. Polymer Engineering and Science, 34(3), 221-228. http://dx.doi.org/10.1002/pen.760340308.

19. Shon, K., \& Bumm, S. H. (2011). Polymer blend compounding and processing. In A. I. Isayev (Ed.), Encyclopedia of Polymer Blends: Processing (Vol. 2, pp. 1-26). Weinheim: Wiley-VCH Verlag GmbH \& Co. KGaA. Retrieved in 12 November 2014, from http://www.wiley-vch.de/books/sample/3527319301_c01. pdf

20. Li, Y., \& Shimizu, H. (2009). Toward a stretchable, elastic, and electrically conductive nanocomposite: morphology and properties of poly[styrene-b-(ethylene-co-butylene)-b-styrene]/ multiwalled carbon nanotube composites fabricated by highshear processing. Macromolecules, 42(7), 2587-2593. http:// dx.doi.org/10.1021/ma802662c.

21. Shimizu, H., Li, Y., Kaito, A., \& Sano, H. (2005). Formation of nanostructured PVDF/PA11 blends using high-shear processing. Macromolecules, 38(19), 7880-7883. http://dx.doi.org/10.1021/ ma051395f.

22. Li, Y., \& Shimizu, H. (2011). Fabrication of nanostructured polycarbonate/poly(methyl methacrylate) blends with improved 
optical and mechanical properties by high-shear. Processing Polymer Engineering and Science, 51(7), 1437-1445. http:// dx.doi.org/10.1002/pen.21879.

23. Teyssandier, F., Cassagnau, P., Gerard, J. F., Mignard, N., \& Melis, F. (2012). Morphology and mechanical properties of PA12/plasticized starch blends prepared by high-shear extrusion. Materials Chemistry and Physics, 133(2-3), 913-923. http:// dx.doi.org/10.1016/j.matchemphys.2012.01.117.

24. Louizi, M., Massardier, V., Mélis, F., Alcouffe, P., \& Cassagnau, P. (2014). High shear processing of polypropylene/silica nanocomposites: improvement of structure-properties. International Polymer Processing, 29(1), 118-127. http:// dx.doi.org/10.3139/217.2819.

25. Louizi, M., Massardier, V., \& Cassagnau, P. (2014). Contribution of high-shear processing to the compatibilization of (PP/EPR)/ PE ternary blends. Macromolecular Materials and Engineering, 299(6), 674-688. http://dx.doi.org/10.1002/mame.201300268.

26. Bouaziz, A., Jaziri, M., Dalmas, F., \& Massardier, V. (2014). Nanocomposites of silica reinforced polypropylene: Correlation between morphology and properties. Polymer Engineering and Science, 54(9), 2187-2196. http://dx.doi.org/10.1002/ pen. 23768 .

27. Vergnes, B., Valle, G. D., \& Delamare, L. (1998). A global computer software for polymer flows in corotating twin screw extruders. Polymer Engineering and Science, 38(11), 17811792. http://dx.doi.org/10.1002/pen.10348.

28. Gendron, R., \& Binet, D. (1998). State of dispersion: Polypropylene filled with calcium carbonate. Journal of Vinyl and Additive Technology, 4(1), 54-59. http://dx.doi.org/10.1002/vnl.10011.

29. Chen, G. H., Li, Y., \& Shimizu, H. (2007). Ultrahigh-shear processing for the preparation of polymer/carbon nanotube composites. Carbon, 45(7), 2334-2340. http://dx.doi.org/10.1016/j. carbon.2007.07.017.

30. Li, Y., \& Shimizu, H. (2007). High-shear processing induced homogenous dispersion of pristine multiwalled carbon nanotubes in a thermoplastic elastomer. Polymer, 48(8), 2203-2207. http:// dx.doi.org/10.1016/j.polymer.2007.02.066.
31. Domenech, T., Peuvrel-Disdier, E., \& Vergnes, B. (2012). Influence of twin screw processing conditions on structure and properties of polypropylene-organoclay nanocomposites. International Polymer Processing, 27(5), 517-526. http://dx.doi. org/10.3139/217.2591.

32. Villmow, T., Kretzschmar, B., \& Pötschke, P. (2010). Influence of screw configuration, residence time, and specific mechanical energy in twin-screw extrusion of polycaprolactone/multiwalled carbon nanotube composites. Composites Science and Technology, 70(14), 2045-2055. http://dx.doi.org/10.1016/j. compscitech.2010.07.021.

33. Serpe, G., Jarrin, J., \& Dawans, F. (1990). Morphologyprocessing relationships in polyethylene-polyamide blends. Polymer Engineering and Science, 30(9), 553-565. http:// dx.doi.org/10.1002/pen.760300908.

34. Bouaziz, A., Massardier, V., Louizi, M., \& Jaziri, M. (2015). Reinforcement of polyolefins-based nanocomposites: combination of compatibilizer with high shear extrusion process. Polymer Engineering and Science, 55(10), 2328-2338. http://dx.doi. org/10.1002/pen.24120.

35. Wu, S. H. (1987). Formation of dispersed phase in incompatible polymer blends: interfacial and rheological effects. Polymer Engineering and Science, 27(5), 335-343. http://dx.doi. org/10.1002/pen.760270506.

36. Liu, J., Tang, G., Qu, G., Zhou, H., \& Guo, Q. (1993). Crystallization of rare earth oxide-filled polypropylene. Journal of Applied Polymer Science, 47(12), 2111-2116. http://dx.doi. org/10.1002/app.1993.070471204.

37. Xiaomin, Z., Jingshu, L., Zhihui, Y., \& Jinghua, Y. (1996). Rheological properties and crystallization behavior of yittrium oxide filled low ethylene content polypropylene copolymer. Journal of Applied Polymer Science, 62(2), 313-318. http:// dx.doi.org/10.1002/(SICI)1097-4628(19961010)62:2<313::AIDAPP6>3.0.CO;2-\#.

Received: Nov. 12, 2014

Revised: Apr. 09, 2015

Accepted: May 25, 2015 


\section{Abbreviations}

ABS: Acrylonitrile Butadiene Styrene resins

DSC: Differential Scanning Calorimetry

EVA: Ethyl Vinyl Acetate copolymer

FR: Flame Retardant

LDPE: Low Density Polyethylene

HDPE: High Density Polyethylene

NIR: Near Infra Red

PET: Poly(ethylene terephtalate)

PP: Polypropylene

PS: Polystyrene

PVC: Poly(Vinyl Chloride)

RSD: Relative Standard Deviation

SEM: Scanning Electron Microscopy

UV: Ultra Violet

$\chi_{c}:$ Crystallisation Degree

XRF: X-Ray Fluorescence 